\title{
Adolescent selfie: an Italian Society of Paediatrics survey of the lifestyle of teenagers
}

\author{
Martina Smorti ${ }^{*}$ D, Annarita Milone ${ }^{2}$, José Gonzalez Gonzalez ${ }^{3}$ and Giovanni Vitali Rosati ${ }^{4}$
}

\begin{abstract}
Background: Epidemiological studies worldwide indicate that teenagers are at risk of internalizing and externalizing problems that persist into adulthood. In our country, there are few epidemiological studies on adolescents internalizing and externalizing problems. These studies, however, were not conducted in all of Italy. The aim of this study, promoted by the Italian Society of Paediatrician (SIP), was to investigate: a) the lifestyle and the prevalence of internalizing and externalizing problems in Italian teenagers and b) the risk and protective factors in family and social contexts. A further aim was to analyse gender differences in the above-mentioned variables.

Methods: 11,527 adolescents aged 13 to 21 years were recruited among students of Italian high schools. Participants were contacted by school authorities inviting them to participate in an internet survey on youth health and lifestyle. If they agreed to participate, the adolescents filled out an on-line anonymous questionnaire. The questionnaire was composed of 60 multiple choice items to investigate nutrition, body perception and lifestyle, internet exposure and sexual behaviour, externalizing and internalizing problems, family context and social context. Participation in the study was completely voluntary. The statistical significance of gender differences was tested by means of Chi-square analyses. Results displayed that Italian female adolescents are at risk of internalizing problems while males are at higher risk of externalizing problems. Moreover, several risk factors emerged from the family context in terms of violence, physical and psychological abuse.
\end{abstract}

Conclusions: It is critical to make paediatricians and schools aware of the main points to improve prevention and healthcare in the teenage population. To our knowledge, this is the first study in the Italian context to enrol more than 11,000 adolescents.

Keywords: Adolescents, Body perception, Sexual behaviour, Mental health, Internalizing problems, Externalizing problems, Family violence

\section{Background}

Epidemiological studies worldwide indicate that up to one in five children and teenagers experience mental health problems that persist into adulthood $[1,2]$. Up to one half of all mental health problems have their onset before the age of 14, and mental illnesses that emerge before adulthood impose a 10-fold higher cost than those that emerge later in life [3].

The presence of mental health problems in children and teenagers negatively influences their well-being,

\footnotetext{
* Correspondence: martina.smorti@unipi.it

${ }^{1}$ Department of Surgical, Medical and Molecular Pathology and Critical Care, University of Pisa, Via Savi 10, 56126 Pisa, Italy

Full list of author information is available at the end of the article
}

causing internalizing and externalizing problems. In psychology, the distinction between internalizing and externalizing problems is often used to distinguish symptoms directed to oneself (or internalizing), such as depression, anxiety and social withdrawal, from behaviours outer-directed (or externalizing), such as rule-breaking, aggression, impulsivity, and defiance $[4,5]$.

The relevance of externalizing problems may be explained with the fact that adolescence is physiologically characterized by an amplification of desire, the impulse for new experiences, and the research of extreme emotions (sensation seeking, novelty seeking, exploration). The complex set of neurobiological, neuropsychological, emotional and relational characteristics typical of 
adolescence can favour access to new experiences, which may include an initiation to alcohol and the use of other drugs [6].

Internalizing and externalizing problems, which are associated with lower academic achievement, school failure, social rejection and marginality [7, 8], affect adolescent males and females differently. In fact, while internalizing problems seem to be especially prevalent among girls, externalizing disorders seem to be common among boys $[1,9]$.

Several risk factors have been identified for the health of children and teenagers. It has been shown that poor economic conditions (lower socio-economic status, worsening of economic inequality), a poor family context (single parenting, parental conflicts, parental mental health problems, parental disorders due to abuse of substances), a negative parenting style (lack of monitoring and involvement, harsh parenting, neglect, victimization), as well as the affiliation to deviant peer context, constitute significant risk factors for the development of internalizing and externalizing problems $[10,11]$.

Despite the widespread recognition of the importance of mental health promotion and prevention in children and teenagers, there is, in many countries, a gap between needs and resource availability. Accumulating evidence suggests that early intervention can provide long-term health and socioeconomic benefits by prevention of the onset of mental health problems and their development into chronic disorders [12].

Although there is an ever-greater definition in nosographic, etiopathogenetic, and neurobiological terms of the onset of clinical entities in the developmental age, there is currently a large series of children that do not come to neuropsychiatric or psychological attention. Sometimes they stop at the first contact with professionals who do not specifically deal with mental health in the developmental age (paediatrician, general practitioner, paramedical, etc.), not accessing the possibility of a diagnostic and therapeutic pathway that could reduce the risk of chronic illnesses and unfavourable prognosis $[12,13]$. The data described show us that it is extremely important to disseminate knowledge of the mental health needs of children and teenagers, and the prevalence, semiology, and risk factors of mental health problems. In particular, training and supervision of non-mental health professionals working with children in the identification and management of mental health problems is indicated as a strategy to improve prevention in child and adolescent mental health [13, 14].

In our country, there are few epidemiological studies that have attempted to provide a general overall view on mental health in the developmental years and, in particular, regarding the pre-adolescent and adolescent age with a view to assessing areas of particular criticality in the population, with objectives of assessment, prevention and intervention.

In Italy, the PRISMA study [15] estimated a prevalence and correlation of mental health problems in 3418 urban preadolescents, living in areas of central and northern Italy. The study revealed a prevalence of $9,8 \%$ of emotional disorders according to DSM-IV and a prevalence of $8,2 \%$ of externalizing disorders. The overall prevalence of mental disorders in Italian teenagers was similar to that found in other studies conducted in European countries. However, few studies analysed the prevalence and impact of internalizing and externalizing problems in a sample representative of the whole Italian adolescent population. Moving from previous considerations, the aim of this study was to investigate, in a representative sample of the entire Italian youth population, the lifestyle and the prevalence of internalizing and externalizing problems, and the factors in family and social context that may increase the risk of developing these problems.

\section{Method}

This study was promoted by the Italian Society of Paediatrics and extended from a regional study aimed at investigating the adolescent lifestyle in Tuscany [16]. With the purpose of extending the investigation to the lifestyle of the Italian adolescent population, in order to improve prevention and healthcare in the youth population, we aimed to investigate: a) lifestyle (related to nutrition, internet use, sexual activities and health behaviour) and the prevalence of internalizing and externalizing problems in Italian teenagers, and $b$ ) the risk and protective factors in family and social contexts. A further aim of this study was to analyse gender differences in the above-mentioned variables.

\section{Setting}

The study took place from January to June 2017 in school settings. Participants were recruited among high school students (aged 13 or more) belonging to different geographical areas of Italy.

\section{Materials and procedures}

A multidisciplinary working group coordinated by the Italian Society of Paediatrics and made up of paediatricians, psychologists, epidemiologists, child psychiatrists, and sociologists who worked at universities or public health departments, developed an online survey composed of 60 multiple choice questions. The questionnaire was focused on increasing the knowledge of attitudes and practices of a population of teenagers who attended Italian high schools or secondary schools about: 
1. Body perception, nutrition and health behaviour: 8 questions to investigate dietary habits (related to breakfast, snack and lunch), the perception of body weight (normal weight, underweight, overweight) reported from the teenagers and from paediatricians, and the practice of sports activities.

2. Internet exposure and sexual behaviour: 10 questions to investigate the age of receiving the first smartphone and the frequency of internet use and misuse (remaining online longer than desired, negative internet influence on studies, perception of finding reliable information online) and the frequency of sexual behaviour (using contraceptives, practicing sex to gain an economic advantage, receiving sexual proposals from adults via dating apps.) (response on a Likert scale from $1=$ never to $5=$ always).

3. Externalizing and internalizing problems: 10 questions to investigate the frequency of externalizing (to undergo or carry out acts of bullying or cyberbullying, smoking cigarettes, using drugs, abusing alcohol) and internalizing (feelings of intense psychological sufferance, perform acts of self-harm) problems (response on a Likert scale from $1=$ never to $5=$ always).

4. Family context: 10 questions to investigate: a) the family context of the teenager (with indication of the family members they live with) or non-family (shelter house or refuge for young) (3 items); b) how often they were witnesses of arguments, abuse, or violence in family ( 3 items, responses on the Likert scale from $1=$ never to $5=$ always); c) how often they turn to parents in case of problems or difficulties (2 items, response on a Likert scale from $1=$ never to $5=$ always); d) perception of the quality of relationships with both parents, and attention received in the family ( 2 items, response on a Likert scale from $1=$ very bad to $5=$ very good).

5. Social context: 11 questions to investigate how often adolescents: a) believe that social and school contexts are receptive to the youth's needs, b) perceive support from friends in case of difficulty, c) prefer "on-line" interactions compared to real ones, d) use internet to communicate (response on a Likert scale from $1=$ never to $5=$ always). In addition, there were two questions to investigate the need for psychological support and the consultation of a psychologist. Finally, one question asked about membership in groups or associations.

In addition to this data, socio-demographic information was collected (gender, age, place of residence, place of birth (Italy / foreign country).

The Italian Society of Paediatricians, involving the regional authorities, contacted all the secondary schools in
Italy, inviting them to inform their students about the on-line questionnaire on youth health and lifestyle. The questionnaire was anonymous, and participation was voluntary.

School authorities explained the aim of the study to students and invited them to participate. If they agreed, the adolescents completed an on-line questionnaire.

\section{Sample}

11,527 adolescents (49.7\% males) aged from 13 to 21 years (mean age 16.16 s.d. 1.64) were recruited for this study among students of Italian high schools. The breakdown of the sample by geographical area of residence was: $31.6 \%$ (3637) central-northern Italy, 30.5\% southern Italy $(n=3519)$ and $37.9 \%$ the islands area $(n=4371)$. $95 \%$ of the participants were born in Italy (10938), while the remaining $(n=589)$ were born in other countries.

\section{Data analysis}

The SPSS 20 for Windows statistical program was used for all analyses.

Because a majority of the questions in sections 2, 3, 4 and 5 were designed to register the frequency by means of a 5 -point Likert scale from $1=$ never to $5=$ always, we decided to recode the answers of the questionnaire in three alternatives $1=$ never; $2=$ occasionally (answer $2=$ rarely and $3=$ sometimes); $3=$ usually (answer $4=$ very often and $5=$ always). Moreover, because the answers concerning the perception of the quality of the relationship with parents were designed on a Likert scale from $1=$ very bad to $5=$ very good, we decided to recode the answers of the questionnaire in three dimensions $1=$ negative (answer $1=$ very bad and $2=$ bad); $2=$ neutral; $3=$ positive (answer $4=$ good and $5=$ very good).

The statistical significance of gender differences was tested by means of Chi-square analyses. Statistical significance was considered for $p$ value $<.05$.

\section{Results}

The results will be presented in thematic areas:

\section{Body perception, nutrition and health behaviours}

Table 1 displays the gender distribution of body perception, nutrition and health behaviour variables in the study population.

According to paediatricians, the majority $(80,7 \%)$ of teenagers have an adequate weight. However only $65 \%$ of participants perceive themselves normal-weighted; the tendency is to perceive oneself as overweight, in disagreement with the paediatricians' opinion (overweight self-perception $27,7 \%$ vs $11.5 \%$ paediatricians). According to paediatricians, male and female opinions are equally reported in the weight category. However, 
according to personal perception, participants who self-reported overweight are two-thirds females, with a significant difference (Chi square 622,73, $\mathrm{df}=2$, $p<.000)$. Concerning dietary habits, $22,6 \%$ of sample declared never to have breakfast at home, and $16,4 \%$ declared never to have a snack at school. Moreover, $46,6 \%$ of the sample (with a higher proportion of females) do not participate in sports.

\section{Internet exposure and sexual behaviour}

Adolescents of our sample received their first smartphone at the age of 11 (females earlier than males, 11,3 vs $11,6 \mathrm{f}=36,76 ; p<.001)$. The use of the internet suggests in many cases a form of dependency. More than half of the sample remains online for longer than they intended. Females more than males appear to be at risk of overuse and dysfunctional use (they claim to remain online longer than desired) (Chi-square 104,02; $\mathrm{df}=2$; $p$ <.001). The use of internet and social networks negatively affects school performance in $70,7 \%$ of cases. Although $31,9 \%$ of the teenagers declare that the time spent online occasionally influences their studies, for $17,1 \%$, studies are usually negatively conditioned. For males this negative influence is greater than for females (Chi-square 23,42; $\mathrm{df}=2 ; p<.001$ ). About half of the sample $(48,1 \%)$ consider themselves usually able to find reliable information online. Males, more than females, consider themselves always able to find reliable information via Internet (Chi-square 133,40; df $=2 ; \mathrm{p}<.001$ ).

Concerning sexual behaviour, $57,6 \%$ of sample declare to have had sexual intercourse with a higher prevalence of males $(56,7 \%)$ than females. Concerning age, $50 \%$ of adolescents aged 13 ( $n=72$ out of 141), with no gender differences, claimed to have had sexual intercourse. The percentage of teenagers with sexual experience grows with age $(62,7 \%$ at 17 years, $79,3 \%$ at 19 years). Among teenagers with sexual experience, $34,4 \%$ declare that they never use contraceptives during sexual intercourse. However, the percentage of adolescents who "never" use

Table 1 Frequency and percentage for body perception, nutrition and health behaviours variables according to gender

\begin{tabular}{|c|c|c|c|c|}
\hline & & Males $n \%$ & Females n \% & Total $n \%$ \\
\hline \multirow[t]{6}{*}{ Your pediatrician thinks your weigh is } & Underweigh & 414 & 479 & 893 \\
\hline & & $46,40 \%$ & $53,60 \%$ & $7,70 \%$ \\
\hline & Regular & 4650 & 4657 & 9307 \\
\hline & & $50,00 \%$ & $50,00 \%$ & $80,70 \%$ \\
\hline & Overweigh & 660 & 667 & 1327 \\
\hline & & $49,70 \%$ & $50,30 \%$ & $11,50 \%$ \\
\hline \multirow[t]{6}{*}{ What do you think about your weigh? } & Underweigh & 556 & 260 & 816 \\
\hline & & $68,10 \%$ & $31,90 \%$ & $7,10 \%$ \\
\hline & Regular & 4159 & 3361 & 7520 \\
\hline & & $55,30 \%$ & $44,70 \%$ & $65,20 \%$ \\
\hline & Overweigh & 1009 & 2182 & 3191 \\
\hline & & $31,60 \%$ & $68,40 \%$ & $27,70 \%$ \\
\hline \multirow[t]{6}{*}{ Do you have breakfast at home? } & Never & 1139 & 1469 & 2608 \\
\hline & & $47,30 \%$ & $56,30 \%$ & $22,60 \%$ \\
\hline & Sometimes & 1222 & 1475 & 2697 \\
\hline & & $45,30 \%$ & $54,70 \%$ & $23,40 \%$ \\
\hline & Always & 3363 & 2859 & 6222 \\
\hline & & $54,10 \%$ & $45,90 \%$ & $54,00 \%$ \\
\hline \multirow[t]{4}{*}{ Do you have a snack when you are at school? } & Never & 884 & 1010 & 1894 \\
\hline & & $46,70 \%$ & $53,30 \%$ & $16,40 \%$ \\
\hline & almost time & 4840 & 4793 & 9633 \\
\hline & & $50,25 \%$ & $49,75 \%$ & $83,60 \%$ \\
\hline \multirow[t]{4}{*}{ Do you attend sport activities at the moment? } & No & 2162 & 3212 & 5374 \\
\hline & & $40,20 \%$ & $59,80 \%$ & $46,60 \%$ \\
\hline & Yes & 3562 & 2591 & 6153 \\
\hline & & $57,90 \%$ & $42,10 \%$ & $53,40 \%$ \\
\hline
\end{tabular}


Table 2 Frequency and percentage for internet exposure and sexual behavior variables according to gender

\begin{tabular}{|c|c|c|c|c|}
\hline & & $\begin{array}{l}\text { Males } n \\
\%\end{array}$ & $\begin{array}{l}\text { Females } \mathrm{n} \\
\%\end{array}$ & $\begin{array}{l}\text { Total } n \\
\%\end{array}$ \\
\hline \multirow[t]{6}{*}{ Have you ever remain online longer than you expected? } & \multirow[t]{2}{*}{ never } & 594 & 386 & 980 \\
\hline & & $60,60 \%$ & $39,40 \%$ & $8,50 \%$ \\
\hline & \multirow[t]{2}{*}{ occasionally } & 2371 & 2125 & 4496 \\
\hline & & $52,70 \%$ & $47,30 \%$ & $39 \%$ \\
\hline & \multirow[t]{2}{*}{ regularly } & 2759 & 3293 & 6051 \\
\hline & & $45,60 \%$ & $54,40 \%$ & $52,50 \%$ \\
\hline \multirow[t]{6}{*}{ Is your study negatively influenced by on-line activities? } & \multirow[t]{2}{*}{ never } & 1648 & 1727 & 3375 \\
\hline & & $48,80 \%$ & $51,20 \%$ & $29,30 \%$ \\
\hline & \multirow[t]{2}{*}{ occasionally } & 2996 & 3178 & 6174 \\
\hline & & $48,50 \%$ & $51,50 \%$ & $53,60 \%$ \\
\hline & \multirow[t]{2}{*}{ regularly } & 1080 & 898 & 1978 \\
\hline & & $54,60 \%$ & $45,40 \%$ & $17,20 \%$ \\
\hline \multirow[t]{6}{*}{ Do you believe yourself able to find online reliable information? } & \multirow[t]{2}{*}{ never } & 483 & 568 & 1051 \\
\hline & & $46,00 \%$ & $54,00 \%$ & $9,10 \%$ \\
\hline & \multirow[t]{2}{*}{ occasionally } & 2175 & 2748 & 4923 \\
\hline & & $44,20 \%$ & $55,80 \%$ & $42,70 \%$ \\
\hline & \multirow[t]{2}{*}{ regularly } & 3066 & 2487 & 5553 \\
\hline & & $55,20 \%$ & $44,80 \%$ & $48,20 \%$ \\
\hline \multirow[t]{4}{*}{ Have you ever had sexual intercourse? } & \multirow[t]{2}{*}{ No } & 1963 & 2925 & 4888 \\
\hline & & $40,20 \%$ & $59,80 \%$ & $42,40 \%$ \\
\hline & \multirow[t]{2}{*}{ yes } & 3761 & 2878 & 6639 \\
\hline & & $56,70 \%$ & $43,30 \%$ & $57,60 \%$ \\
\hline \multirow[t]{6}{*}{ Do you use contraceptive methods? } & \multirow[t]{2}{*}{ never } & 1205 & 1082 & 2287 \\
\hline & & $52,70 \%$ & $47,30 \%$ & $34,40 \%$ \\
\hline & \multirow[t]{2}{*}{ occasionally } & 717 & 461 & 1178 \\
\hline & & $60,90 \%$ & $39,10 \%$ & $17,70 \%$ \\
\hline & \multirow[t]{2}{*}{ regularly } & 1839 & 1335 & 3174 \\
\hline & & $57,90 \%$ & $42,10 \%$ & $47,80 \%$ \\
\hline \multirow[t]{4}{*}{ Did you have a sexual education in family? } & \multirow[t]{2}{*}{ No } & 3531 & 3552 & 7083 \\
\hline & & $49,90 \%$ & $50,10 \%$ & $61,40 \%$ \\
\hline & \multirow[t]{2}{*}{ yes } & 2193 & 2251 & 4444 \\
\hline & & $49,30 \%$ & $50,70 \%$ & $38,60 \%$ \\
\hline \multirow[t]{6}{*}{ Have you ever received sexual proposed by adults via the meetings app.? } & \multirow[t]{2}{*}{ never } & 4943 & 4929 & 9872 \\
\hline & & $50,10 \%$ & $49,90 \%$ & $85,60 \%$ \\
\hline & \multirow[t]{2}{*}{ occasionally } & 551 & 670 & 1221 \\
\hline & & $45,10 \%$ & $54,90 \%$ & $10,60 \%$ \\
\hline & regularly & 230 & 204 & 434 \\
\hline & & $53,00 \%$ & $47,00 \%$ & $3,80 \%$ \\
\hline Have you ever give sexual service in exchange of payment? & never & 5474 & 5687 & 11,161 \\
\hline & & $49,00 \%$ & $51,00 \%$ & $96,80 \%$ \\
\hline & occasionally & 250 & 116 & 366 \\
\hline & & $68,30 \%$ & $31,70 \%$ & $3,20 \%$ \\
\hline & regularly & 0 & 0 & 0 \\
\hline
\end{tabular}


Table 2 Frequency and percentage for internet exposure and sexual behavior variables according to gender (Continued)

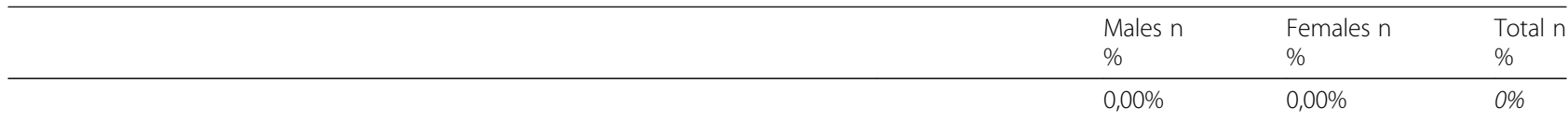

Note: Percentage are reported for males and females while percentage in italic are reported for total sample

contraceptives decreases with age, going from $69,4 \%$ at 13 years to $46,9 \%$ at 15 years to $20 \%$ to 19 years of age. Concerning gender, males declare that they use contraceptives more often than females (Chi-square 25,286; $\mathrm{df}$ $=2 ; p<.001) .61,4 \%$ of the sample declares not to have received any sexual education in the family.

$14,4 \%$ of the total sample declared to have received sexual proposals from adults by "dating" apps, and 3,2\% declared to have offered sex in exchange for payment. Participants who reported to offer sex in exchange for payment are two-thirds males. This difference between males and females is statistically significant (Chi-square $52,59 ; \mathrm{df}=1 ; p<.001)$. Table 2 displays the gender distribution of internet exposure and sexual behavior in the study population.

\section{Externalizing and internalizing problems}

$36,8 \%$ of the sample declares that they smoke cigarettes and in $17 \%$ of cases they smoke regularly. The percentage of female smokers is significantly higher than males (Chi-square 31,13; $\mathrm{df}=2 ; p<.001$ ).

Concerning binge drinking, although $61.3 \%$ of the participants report never binge drinking, 8,8\% declare regular binge drinking. Males reported binge drinking behaviour more frequently than females $(55,9 \%$ vs. 44,1\%) (Chi-square 22,51; $\mathrm{df}=2 ; p<.001$ ).

Regarding drug use, $22.3 \%$ of the sample claims they have used drugs at least once and in 6,5\%, the consumption has been regular. The intake of drugs is more frequent in males (Chi-square 47,36; $\mathrm{df}=2 ; \mathrm{p}<.001$ ).

6687 participants affirmed to have been victims of bullying or cyberbullying. $33,7 \%$ of the sample reported to have been bullied, and $12,6 \%$ reported having been cyberbullied at least once. In $67 \%$ of cases, bullied or cyberbullied teenagers did not talk with anyone about their victimization.

The percentage of females who reported to "regularly" be victims of bullying and cyberbullying episodes is significantly higher than males (victim of bullying Chi-square 37,09; $\mathrm{df}=2 ; p<.001$; victim of cyberbullying Chi-square 110,59; $\mathrm{df}=2 ; p<.001)$. The percentage of males who reported to "regularly" be bullied or cyberbullied is significantly higher than females (Chi-square 23,$24 ; \mathrm{df}=2 ; p<.001$ ).

$15,3 \%$ of the sample ( $n=1759$ teenagers) claims to have intentionally self-injured at least once. Females reported self-harm significantly more often than males, occasionally and regularly (Chi-square 104,03; $\mathrm{df}=2 ; \mathrm{p}$ $<.001$ ). $6 \%$ of the sample reported to "regularly" feel intense psychological suffering. Females reported this regular suffering three times more than males did (chi square $331 ; \mathrm{df}=2 ; \mathrm{p}<.001$ ). Table 3 displays the geneder distribution of internalizing and externalizing problems.

\section{Family context}

Concerning the residential situation, about 8 adolescents out of 10 live with both parents, while 1 in 10 live in single-parent families. There are also 3,8\% of the sample living in reconstituted families (own parent and his/ her new partner) and a 3,2\% living in an "other" situation. $3,4 \%$ of the sample declare to have a family made up of same-gender parents. $6,6 \%$ of the sample have lived for a short period in a shelter house.

$22 \%$ of participants declared to regularly be witness to their parents' quarrels. A quarter of the participants reported at least one physical and/or psychological aggression episode in the family context. In most cases $(61,7 \%)$, this aggression was carried out by the parents (the father 3 times more frequently than the mother), but the percentage of teenagers who report aggression by their brothers $(11,4 \%)$, uncles $(3,6 \%)$ or grandparents $(3,6 \%)$ is significant. $13,4 \%$ of young people report that they have been victims of physical violence in their families, which in $2,9 \%$ of cases happens regularly.

Gender differences emerged in the family climate with females reporting to be witnesses of parental quarrels more often than males (Chi square 179,89 df.2; $p=.001$ ), reporting a higher degree of family aggression (Chi square 65,$81 ; \mathrm{df} .2 ; p<.001$ ), and stating to be victims of physical and psychological aggression more than males (Chi square 19,45; df.2; $\mathrm{p}=.001$ ).

The relationship with parents is defined globally positive, with the mother receiving a more positive evaluation. The relationship with the father is negatively evaluated in $18 \%$ of the sample, while that with the mother in only $8,9 \%$. Regarding the sensitive issues that worry teenagers and communication in the family, $46,8 \%$ declare that they usually turn to their parents to talk about things that worry them. Females declare that they turn more to their parents in case of difficulty than males (Chi square 18,30; df. 2; $p<.001$ ). Table 4 displays the gender distribution of family context variables. 
Table 3 Frequency and percentage for externalizing and internalizing problems variables according to gender

\begin{tabular}{|c|c|c|c|c|}
\hline & & $\begin{array}{l}\text { Males n } \\
\%\end{array}$ & $\begin{array}{l}\text { Females n } \\
\%\end{array}$ & $\begin{array}{l}\text { Total n } \\
\%\end{array}$ \\
\hline \multirow[t]{6}{*}{ Do you smoke cigarettes? } & never & 3792 & 3565 & 7357 \\
\hline & & $51,50 \%$ & $48,50 \%$ & $63,80 \%$ \\
\hline & occasionally & 999 & 1209 & 2208 \\
\hline & & $45,20 \%$ & $54,80 \%$ & $19,20 \%$ \\
\hline & regularly & 933 & 1029 & 1962 \\
\hline & & $47,60 \%$ & $52,40 \%$ & $17 \%$ \\
\hline \multirow[t]{6}{*}{ Have you ever been a binge drinker? } & never & 3414 & 3656 & 7070 \\
\hline & & $48,30 \%$ & $51,70 \%$ & $61,30 \%$ \\
\hline & occasionally & 1744 & 1701 & 3445 \\
\hline & & $50,60 \%$ & $49,40 \%$ & $29,90 \%$ \\
\hline & regularly & 566 & 446 & 1012 \\
\hline & & $55,90 \%$ & $44,10 \%$ & $8,80 \%$ \\
\hline \multirow[t]{6}{*}{ Have you ever been a drug user? } & never & 4306 & 4650 & 8956 \\
\hline & & $48,10 \%$ & $51,90 \%$ & $77,70 \%$ \\
\hline & occasionally & 977 & 851 & 1828 \\
\hline & & $53,40 \%$ & $46,60 \%$ & $15,90 \%$ \\
\hline & regularly & 441 & 302 & 743 \\
\hline & & $59,40 \%$ & $40,60 \%$ & $6,40 \%$ \\
\hline \multirow[t]{6}{*}{ Have you ever been a victim of bullism? } & never & 3936 & 3705 & 7641 \\
\hline & & $51,50 \%$ & $48,50 \%$ & $66,30 \%$ \\
\hline & occasionally & 1519 & 1721 & 3240 \\
\hline & & $46,90 \%$ & $53,10 \%$ & $28,10 \%$ \\
\hline & regularly & 269 & 377 & 646 \\
\hline & & $41,60 \%$ & $58,40 \%$ & $5,60 \%$ \\
\hline \multirow[t]{6}{*}{ Have you ever been a victim of cyberbullism? } & never & 5188 & 4884 & 10,072 \\
\hline & & $51,50 \%$ & $48,50 \%$ & $87,40 \%$ \\
\hline & occasionally & 426 & 752 & 1178 \\
\hline & & $36,20 \%$ & $63,80 \%$ & $10,20 \%$ \\
\hline & regularly & 110 & 167 & 277 \\
\hline & & $39,70 \%$ & $60,30 \%$ & $2,40 \%$ \\
\hline \multirow[t]{6}{*}{ Have you ever been a bully or cyberbully? } & never & 3704 & 3986 & 7690 \\
\hline & & $48,20 \%$ & $51,80 \%$ & $66,70 \%$ \\
\hline & occasionally & 1731 & 1590 & 3321 \\
\hline & & $52,10 \%$ & $47,90 \%$ & $28,80 \%$ \\
\hline & regularly & 289 & 227 & 516 \\
\hline & & $56,00 \%$ & $44,00 \%$ & $4,50 \%$ \\
\hline \multirow[t]{6}{*}{ Have you ever feel an intense psychological sufferance? } & Never & 1703 & 777 & 2480 \\
\hline & & $68,7 \%$ & $31,3 \%$ & $67,9 \%$ \\
\hline & Occasionally & 398 & 556 & 954 \\
\hline & & $41,7 \%$ & $58,3 \%$ & $26,12 \%$ \\
\hline & regularly & 57 & 161 & 218 \\
\hline & & $26,1 \%$ & $73,9 \%$ & $6 \%$ \\
\hline Have you ever experimented self-harm? & never & 5045 & 4723 & 9768 \\
\hline
\end{tabular}


Table 3 Frequency and percentage for externalizing and internalizing problems variables according to gender (Continued)

\begin{tabular}{|c|c|c|c|}
\hline & $\begin{array}{l}\text { Males } n \\
\%\end{array}$ & $\begin{array}{l}\text { Females } \mathrm{n} \\
\%\end{array}$ & $\begin{array}{l}\text { Total } n \\
\% \\
\end{array}$ \\
\hline & $51,60 \%$ & $48,40 \%$ & $84,70 \%$ \\
\hline occasionally & 521 & 791 & 1312 \\
\hline & $39,70 \%$ & $60,30 \%$ & $11,40 \%$ \\
\hline regularly & 158 & 289 & 447 \\
\hline & $35,30 \%$ & $64,70 \%$ & $3,90 \%$ \\
\hline
\end{tabular}

Note: Percentage are reported for males and females while percentage in italic are reported for total sample

\section{Social context}

Table 5 shows the gender distribution of social context variables in the study population. The social context, according to teenagers, allows them to have complete freedom of expression. This freedom is "usually" perceived in $51,7 \%$ of cases. Moreover, males, more than females, believe that social context allows freedom of expression (Chi square 78,88; df. 2; $p<.001)$. The school seems distant from the teenagers' need; about half of the sample $(51,4 \%)$, in fact, reports that the school is "never" receptive to the problems of teenagers. Males, more than females, report positive opinions on the attention of the school to the problems of boys (Chi square 18,30; df. 2; $p<.001$ ). The teenagers of the sample claim to have needed psychological support in $50,6 \%$ of cases, but only in $15,8 \%$ of cases this need was matched by a real psychological evaluation. Females, compared to males, reported a greater need for psychological support (Chi square 467,03; df 2; $p$ $<.001$ ), as well as a greater use of psychological services (Chi-square 75,61; df $1 ; \mathrm{p}<.001$ ).

More support seems to come from friends. Most of the teenagers $(58,3 \%)$ declared that they usually turn to friends in case of problems and receive help from them in case of difficulty $(70,2 \%)$. Females reported that they talk with friends in case of problems more "regularly" than males (Chi square $170,03 ; \mathrm{df}=2 ; p<.001)$, and that they receive help from them (Chi-square 33,83; $\mathrm{df}=2 ; \mathrm{p}<.001$ ). In moments of loneliness, $35,8 \%$ of teenagers report using internet or social networks to talk to others, and in females this happens more frequently (Chi square 245,30; df $=2 \mathrm{p}<.001)$.

Social relationships take place both in informal and formal groups. $35,7 \%$ of the sample $(n=4113)$, in fact, claims to be members of youth associations. The most frequently attended associations are scouting (secular or religious) $(37,7 \%)$, sport $(18,2 \%)$, or regional traditions $(10,1 \%)$.

Real social relationships are usually preferred to virtual ones, but about 1 adolescent in 10 (9,2\%) declares to "always" prefer online interactions rather than face to face. There is no difference between males and females.

\section{Discussion}

The survey proposed in this paper provides new and interesting data about the characteristics of Italian teenagers, underlining the importance of prevention, support, information and training of all professionals who deal with physical and mental health of childhood.

Concerning body perception, although according to paediatricians 8 teenagers out of 10 have an adequate weight, only 6 out of 10 perceive themselves as normal-weight. Teenagers tend to perceive themselves as overweight. This tendency is higher in females compared to males. Moreover, females report dietary restrictions aimed at reducing intake and, consequently, reducing their weight. Young age, female gender, overweight misperception, and being on a diet are some of the few identified risk factors that have been reliably linked to the development of eating disorders [17, 18]. Thus, some teenagers may progress from initial attempts to control their weight to unhealthy dietary restrictions, even to starvation. Weight loss is often reinforced by media models of shape, and peer and family environments, but an excessive preoccupation with body imagine can lead to incomplete eating disorders and other psychopathological problems (social isolation, irritability, difficulty of concentrating). Body dissatisfaction and desire of a thinner figure are described in young boys and girls, and early teenagers may endorse an image of a thin body model, promoted by media, as a desirable standard to achieve [19].

The findings of this research are consistent with literature, pointing out the importance of carrying out preventive interventions on eating disorders, in terms of dissemination of indications for a correct diet in adolescence, and in interception of populations at risk.

The second part of the study was aimed at investigating internet exposure and sexual behaviours. Our results showed that Italian adolescents received their first smartphones at the age of 11 . As digital natives, adolescents use smartphones to express their thoughts in an online space and search for emotional relationships in the pursuit of instant reactions and feedback. However, given their immature competence of control, teenagers resulted to be at high risk of smartphone addiction. 
Table 4 Frequency and percentage for family context variables according to gender

\begin{tabular}{|c|c|c|c|c|}
\hline & & Males n \% & Females n \% & Total n \% \\
\hline \multirow[t]{10}{*}{ Who do you live with? } & \multirow[t]{2}{*}{ Both parents } & 4802 & 4802 & 9604 \\
\hline & & $50,0 \%$ & $50,0 \%$ & $83,3 \%$ \\
\hline & \multirow[t]{2}{*}{ Mother } & 438 & 526 & 964 \\
\hline & & $45,4 \%$ & $54,6 \%$ & $8,4 \%$ \\
\hline & \multirow[t]{2}{*}{ Father } & 79 & 67 & 146 \\
\hline & & $54,1 \%$ & $45,9 \%$ & $1,3 \%$ \\
\hline & \multirow[t]{2}{*}{1 parent + a new partner } & 210 & 233 & 443 \\
\hline & & $47,4 \%$ & $52,6 \%$ & $3,8 \%$ \\
\hline & \multirow[t]{2}{*}{ Other } & 195 & 175 & 370 \\
\hline & & $52,7 \%$ & $47,3 \%$ & $3,2 \%$ \\
\hline \multirow[t]{8}{*}{ Your family consists of: } & \multirow[t]{2}{*}{ Same gender parents } & 183 & 214 & 397 \\
\hline & & $46,1 \%$ & $53,9 \%$ & $3,4 \%$ \\
\hline & \multirow[t]{2}{*}{ Different gender parents } & 5223 & 5208 & 10,431 \\
\hline & & $50,1 \%$ & $49,9 \%$ & $90,5 \%$ \\
\hline & \multirow[t]{2}{*}{ Single parent } & 237 & 300 & 537 \\
\hline & & $44,1 \%$ & $55,9 \%$ & $4,7 \%$ \\
\hline & \multirow[t]{2}{*}{ Other } & 81 & 81 & 162 \\
\hline & & $50 \%$ & $50 \%$ & $1,4 \%$ \\
\hline \multirow[t]{4}{*}{ Have you ever lived in a shelter House? } & \multirow[t]{2}{*}{ No } & 5318 & 5452 & 10,770 \\
\hline & & $49,40 \%$ & $50,60 \%$ & $93,40 \%$ \\
\hline & \multirow[t]{2}{*}{ Yes } & 406 & 351 & 757 \\
\hline & & $53,60 \%$ & $46,40 \%$ & $6,60 \%$ \\
\hline \multirow[t]{6}{*}{ Have you ever been a testimonial of argue in family? } & \multirow[t]{2}{*}{ never } & 1679 & 1309 & 2988 \\
\hline & & $56,20 \%$ & $43,80 \%$ & $25,90 \%$ \\
\hline & \multirow[t]{2}{*}{ occasionally } & 3067 & 2938 & 6005 \\
\hline & & $51,10 \%$ & $48,90 \%$ & $52,10 \%$ \\
\hline & \multirow[t]{2}{*}{ regularly } & 978 & 1556 & 2534 \\
\hline & & $38,60 \%$ & $61,40 \%$ & $22 \%$ \\
\hline \multirow[t]{6}{*}{ Have you ever been a testimonial of Violence in family? } & \multirow[t]{2}{*}{ never } & 4429 & 4221 & 8650 \\
\hline & & $51,20 \%$ & $48,80 \%$ & $75,00 \%$ \\
\hline & \multirow[t]{2}{*}{ occasionally } & 996 & 1063 & 2059 \\
\hline & & $48,40 \%$ & $51,60 \%$ & $17,90 \%$ \\
\hline & \multirow[t]{2}{*}{ regularly } & 299 & 519 & 818 \\
\hline & & $36,60 \%$ & $63,40 \%$ & $7,10 \%$ \\
\hline \multirow[t]{6}{*}{ Have you ever been a victim of Violence? } & \multirow[t]{2}{*}{ never } & 4933 & 5050 & 9983 \\
\hline & & $49,40 \%$ & $50,60 \%$ & $86,60 \%$ \\
\hline & occasionally & 652 & 554 & 1206 \\
\hline & & $54,10 \%$ & $45,90 \%$ & $10,50 \%$ \\
\hline & regularly & 139 & 199 & 338 \\
\hline & & $41,10 \%$ & $58,90 \%$ & $2,90 \%$ \\
\hline How do you describe your relationship with your father? & negative & 451 & 591 & 1042 \\
\hline & & $43,30 \%$ & $56,70 \%$ & $18,00 \%$ \\
\hline & neutral & 430 & 430 & 860 \\
\hline & & $50,00 \%$ & $50,00 \%$ & $14,80 \%$ \\
\hline
\end{tabular}


Table 4 Frequency and percentage for family context variables according to gender (Continued)

\begin{tabular}{|c|c|c|c|c|}
\hline & & Males n \% & Females n \% & Total n \% \\
\hline & positive & 2157 & 1735 & 3892 \\
\hline & & $55,40 \%$ & $44,60 \%$ & $67,20 \%$ \\
\hline \multirow[t]{6}{*}{ How do you describe your relationship with your mother? } & negative & 276 & 248 & 524 \\
\hline & & $52,70 \%$ & $47,30 \%$ & $8,90 \%$ \\
\hline & neutral & 296 & 359 & 655 \\
\hline & & $45,20 \%$ & $54,80 \%$ & $11,20 \%$ \\
\hline & positive & 2494 & 2192 & 4686 \\
\hline & & $53,20 \%$ & $46,80 \%$ & $79,90 \%$ \\
\hline \multirow[t]{6}{*}{ Do you turn to your parents in case of difficulty? } & never & 819 & 748 & 1567 \\
\hline & & $52,30 \%$ & $47,70 \%$ & $13,60 \%$ \\
\hline & occasionally & 2343 & 2230 & 4573 \\
\hline & & $51,20 \%$ & $48,40 \%$ & $39,70 \%$ \\
\hline & regularly & 2562 & 2825 & 5387 \\
\hline & & $47,60 \%$ & $52,40 \%$ & $46,70 \%$ \\
\hline
\end{tabular}

Note. Percentage are reported for males and females while percentage in italic are reported for total sample

Paediatricians should encourage parents to think about giving their children a smartphone at an early age, given that this instrument seems to be difficult to handle. Teenagers (especially females) seem to be at risk of overuse and dysfunctional use of smartphones (they claim to regularly remain online longer than desired) and this negatively affects school performance.

With respect to sexual habits, our findings showed a certain precociousness of activation in this area which is accompanied by reduced awareness of risks, and consequent poor use of contraceptives. The sample shows how, even today, sex education in our country does not occur in the family or school contexts, but rather according to the indications of peers, which do not ensure adequate education. These data invite us to reflect on how important it is for paediatricians and all people who work with youth to promote interventions to help the parents of pre-adolescent and adolescent children give correct sex education to their children $[29,30]$.

An alarming fact is that $3,2 \%$ of teenagers have had sexual experiences to gain economic benefits and 14,4\% have received sexual proposals by adults, mainly through social networks or dating apps. Once more, these data suggest the risk of internet exposure for Italian youth. In fact, although the adolescents consider themselves able to find reliable information online, our findings suggest that they are not able, given that they received sexual proposals by adults via apps, and they reported to be victims of cyberbullying.

The third part of the study was aimed at increasing our knowledge of externalizing and internalizing problems. Concerning drug consumption, our study showed that 2 adolescents out of 10 had consumed drugs at least once. Moreover, 6,5\% of teenagers stated a regular consumption of drugs, and 8,8\% declared regular binge drinking. Both the regular binge drinking and drug consumption are more frequent in males than females.

The relevance of these data is given by the consequences that repeated binge drinking and drug consumption have on an adolescent's health. Early and repeated binge drinking, in fact, is associated to a decay of the attentive function and a decrease of cognitive performance in verbal learning and short-delay memory tasks with a linear dose-dependent relationship. Further, substance exposure during adolescence may adversely affect cognitive functioning, and marijuana users have attention deficit [20], poorer performance on working memory, verbal learning and memory. Moreover, poorer performance in visuospatial functioning and psychometric motor speed tasks have been observed with higher doses and an earlier age of onset [21-23]. In literature, the use of cannabis has been confirmed as a risk factor to use other illicit drugs [24]. Our data also show that females report a higher frequency of cigarette smoking than males. These data are particularly interesting given the close link between the precocity of this behaviour and the increased risk of tobacco dependence with consequent long-term effects [25]. Even a brief exposure to nicotine during the adolescent period can have long-lasting effects on neurochemistry and behaviour, including decreased cognitive function, and could enhance drug reward [26, 27]. Early intervention should be developed, especially in the female population, which, according to our data, resulted to be at higher risk. In fact, epidemiological data have consistently demonstrated that women have less success quitting tobacco use, a higher risk of developing tobacco-related disease, and are especially sensitive to the adverse effects of nicotine withdrawal [28]. 
Table 5 Frequency and percentage for social context variables according to gender

\begin{tabular}{|c|c|c|c|c|}
\hline & & $\begin{array}{l}\text { Males n } \\
\%\end{array}$ & $\begin{array}{l}\text { Females } \mathrm{n} \\
\%\end{array}$ & $\begin{array}{l}\text { Total } n \\
\%\end{array}$ \\
\hline \multirow[t]{6}{*}{ Do you believe that the social context allow you freedom of expression? } & \multirow[t]{2}{*}{ never } & 434 & 381 & 815 \\
\hline & & $53,3 \%$ & $46,7 \%$ & $7,1 \%$ \\
\hline & \multirow[t]{2}{*}{ occasionally } & 2127 & 2629 & 4756 \\
\hline & & $44,7 \%$ & $55,3 \%$ & $41,3 \%$ \\
\hline & \multirow[t]{2}{*}{ regularly } & 3163 & 2793 & 5956 \\
\hline & & $53,1 \%$ & $46,9 \%$ & $51,7 \%$ \\
\hline \multirow[t]{6}{*}{ Do you believe that the school is receptive to the youth needs? } & \multirow[t]{2}{*}{ never } & 1124 & 1062 & 2186 \\
\hline & & $51,4 \%$ & $48,6 \%$ & $19,0 \%$ \\
\hline & \multirow[t]{2}{*}{ occasionally } & 3365 & 3632 & 6997 \\
\hline & & $48,1 \%$ & $51,9 \%$ & $60,7 \%$ \\
\hline & \multirow[t]{2}{*}{ regularly } & 1235 & 1109 & 2344 \\
\hline & & $52,7 \%$ & $47,3 \%$ & $20,3 \%$ \\
\hline \multirow[t]{6}{*}{ Have you ever felt the need for psychological support? } & \multirow[t]{2}{*}{ Yes } & 3371 & 2323 & 5694 \\
\hline & & $59,2 \%$ & $40,8 \%$ & $49,4 \%$ \\
\hline & \multirow[t]{2}{*}{ No } & 1768 & 2286 & 4054 \\
\hline & & $43,6 \%$ & $56,4 \%$ & $35,2 \%$ \\
\hline & \multirow[t]{2}{*}{ In past } & 585 & 1194 & 1779 \\
\hline & & $32,9 \%$ & $67,1 \%$ & $15,4 \%$ \\
\hline \multirow[t]{2}{*}{ Have you ever consult a psychologist? } & No & $\begin{array}{l}4352 \\
52,1 \%\end{array}$ & $\begin{array}{l}4007 \\
47,9 \%\end{array}$ & $\begin{array}{l}8359 \\
84,2 \%\end{array}$ \\
\hline & Yes & $\begin{array}{l}631 \\
40,1 \%\end{array}$ & $\begin{array}{l}942 \\
59,9 \%\end{array}$ & $\begin{array}{l}1573 \\
15,8 \%\end{array}$ \\
\hline \multirow[t]{6}{*}{ Do you turn to your friend in case of problems or difficulties? } & \multirow[t]{2}{*}{ never } & 679 & 393 & 1072 \\
\hline & & $63,3 \%$ & $36,7 \%$ & $9,3 \%$ \\
\hline & \multirow[t]{2}{*}{ occasionally } & 2024 & 1712 & 3736 \\
\hline & & $54,2 \%$ & $45,8 \%$ & $32,4 \%$ \\
\hline & \multirow[t]{2}{*}{ regularly } & 3021 & 3698 & 6719 \\
\hline & & $45,0 \%$ & $55,0 \%$ & $58,3 \%$ \\
\hline \multirow[t]{6}{*}{ Do you receive help from your friends in case of need? } & \multirow[t]{2}{*}{ never } & 245 & 223 & 468 \\
\hline & & $52,4 \%$ & $47,6 \%$ & $4,1 \%$ \\
\hline & \multirow[t]{2}{*}{ occasionally } & 1598 & 1360 & 2958 \\
\hline & & $54,0 \%$ & $46,0 \%$ & $25,7 \%$ \\
\hline & \multirow[t]{2}{*}{ regularly } & 3881 & 4220 & 8101 \\
\hline & & $47,9 \%$ & $52,1 \%$ & $70,3 \%$ \\
\hline \multirow[t]{6}{*}{ Do you use internet to talk with other people? } & \multirow[t]{2}{*}{ never } & 1467 & 923 & 2390 \\
\hline & & $61,4 \%$ & $38,6 \%$ & $20,7 \%$ \\
\hline & \multirow[t]{2}{*}{ occasionally } & 2544 & 2461 & 5005 \\
\hline & & $50,8 \%$ & $49,2 \%$ & $43,4 \%$ \\
\hline & \multirow[t]{2}{*}{ regularly } & 1713 & 2419 & 4132 \\
\hline & & $41,5 \%$ & $58,5 \%$ & $35,8 \%$ \\
\hline Are you a member of a youth associations? & No & 3933 & 3993 & 7926 \\
\hline & & $49,6 \%$ & $50,4 \%$ & $68,8 \%$ \\
\hline & Yes & 1791 & 1810 & 3601 \\
\hline & & $49,7 \%$ & $50,3 \%$ & $31,2 \%$ \\
\hline
\end{tabular}


Table 5 Frequency and percentage for social context variables according to gender (Continued)

\begin{tabular}{|c|c|c|c|c|}
\hline & & $\begin{array}{l}\text { Males } n \\
\%\end{array}$ & $\begin{array}{l}\text { Females } n \\
\%\end{array}$ & $\begin{array}{l}\text { Total n } \\
\%\end{array}$ \\
\hline \multirow[t]{10}{*}{ If yes, which association are you a member of? } & scout & 217 & 218 & 435 \\
\hline & & $49,9 \%$ & $50,1 \%$ & $10,6 \%$ \\
\hline & Religious association & 486 & 630 & 1116 \\
\hline & & $43,5 \%$ & $56,5 \%$ & $27,1 \%$ \\
\hline & Sport associations & 247 & 502 & 749 \\
\hline & & $33,0 \%$ & $67,0 \%$ & $18,2 \%$ \\
\hline & Traditional association & 237 & 179 & 416 \\
\hline & & $57,0 \%$ & $43,0 \%$ & $10,1 \%$ \\
\hline & Other & 920 & 477 & 1397 \\
\hline & & $65,9 \%$ & $34,1 \%$ & $34,0 \%$ \\
\hline
\end{tabular}

Note. Percentage are reported for males and females rows while percentage in italic are reported for total sample

Concerning bullying, three adolescents out of ten reported to have been bullied, and one of ten reported being cyberbullied at least once in their lives. In most of these cases, bullied or cyberbullied teenagers did not talk with anyone about their victimization. Females are more frequently victims of bullying and cyberbullying, while males tend to assume the bully or cyberbully role. Literature suggests that bullying experiences are typically confined to school, and that the negative consequences of involvement in face-to-face bullying involves psychosocial adjustment [30] and perceptions of school [31]. Moreover, victims of cyberbullying report that they are afraid to go to school [32] and, for some young people, this fear escalates into active avoidance manifested as truancy [33]. Involvement in cyberbullying also results in young people feeling less safe in school [34] and having negative attitudes towards school [35]. Thus, paediatricians should pay particular attention to symptoms of school avoidance and fear of school reported by parents or teenagers, given that they could be signs of bullying.

Finally, $15 \%$ of adolescents claimed to have intentionally self-injured at least once, and females reported this behaviour more frequently than males, accompanied by psychological suffering. Referred to in literature and media as "self-injurious behaviour," "self-injury," "self-harm," "self-mutilation," or "cutting", self-injury is typically defined as the deliberate, self-inflicted destruction of body tissue without suicidal intent and for purposes not socially sanctioned [36]. Research has shown that the location of the self-injury is usually in areas that are hidden by clothing, such as the arms, abdomen, inner thighs, feet, genitals, and torso (especially near the breasts in females). Our results confirm previous results about the reason for self-injuring in terms of reducing psychological pain and expressing and alleviating psychological distress [37]. Given that it has been noted that self-harm is statistically associated with an increased risk of suicide and can result in unanticipated severe harm or fatality [38], paediatricians should be pay attention to cuts or signs of self-harm during medical visits, when teenagers remove their clothes. Future research should explore the family context of adolescents who report self-harm.

Concerning the family context, it must be noted that one in five teenagers are witness to physical or psychological aggression in the family of origin. A lot of research has provided evidence that the parenting context has important implications for teenagers' involvement. Adolescent males who are victims or witnesses of violence exhibit a higher rate of violence perpetration, and a lower level of self-control [39]. On the contrary, adolescent females who are victims are significantly more likely to attempt suicide and self-harm than males. It is estimated that five to six times as many adolescent girls self-harm as compared to boys [40]. Moreover, exposure to violence increases vulnerability to a broad range of mental and physical health problems over the life course; exposure to physical abuse in childhood is associated with a $54 \%$ increase in odds of depressive disorder, a $78 \%$ increase in odds of risky sexual behaviour, and a $32 \%$ increase in odds of obesity. However, despite the relevance of this phenomenon for mental and physical health in adolescents, only a small percentage of these violent incidents are reported to law enforcement, health care clinicians, or child protection agencies. The most effective violence prevention strategies include parent and family-focused programs, early childhood education, school-based programs, therapeutic or counselling interventions, and public policy [41]. Thus, paediatricians should pay particular attention to symptoms of family conflict and violence and, when they think that there is a risk for a negative family environment, they should explore this theme in a private talk with the teenager [42]. 
Our data demonstrated that, in the adolescent's perception, the school seems distant and not receptive to the teenager's needs and problems. This school inadequacy is suffered in a greater measure by girls.

Further, adolescent girls today suffer from internalizing problems, such as somatic symptoms and mental health problems, at higher rates compared to those of previous decades $[1,43]$.

Research shows that mental health problems are currently a public health challenge globally [42] and affect $10-20 \%$ of children and teenagers worldwide [2]. Therefore, we encourage schools to promote an enhanced mental health literacy.

Paediatricians and schools should be equipped with the elements to encourage young people to grow up in an environment where they can feel free to express themselves, and to be listened to, without fear of being judged [44].

In our sample, more than half the teenagers felt the need for psychological support, but only in $15 \%$ of cases was this need met. It is critical that teachers and health professionals be trained to recognize signs and symptoms of psychological distress and children at risk.

The present study should be considered in the light of some limitations. First, this survey analysed only the gender difference neglecting the role of other demographic variables (such as age) may have in promoting different lifestyle. Further research should deep this aspect analysing how the internalizing and externalizing problems vary according to age. Second, this study did not consider the relationship between adolescent lifestyle and family or peer context. Thus, it is not possible, for instance, to know how the family context affects internalizing and externalizing problems in Italian adolescents. In the same direction, our findings did not allow us to understand how the social context (school, peer group both formal or informal) influences the internalizing and externalizing behaviours. Future research should explore the interrelation among variables. However, despite these limitations, this study is very interesting, given that it offers insight into internalizing and externalizing problems in teenagers involving a large population sample from the whole Italian territory.

\section{Conclusions}

This study consisted in a survey of Italian adolescents and, to our knowledge, it is the first investigation that enrolled more than 11,000 teenagers living in the northern, central, southern, and island areas of Italy. Moreover, the findings of this study provide useful indications for health professionals and school authorities to promote health programs. First, a misperception of body image and an overweight perception, especially in female adolescents, constituting a risk factor for subsequent eating disorders, should be attentively evaluated and discussed with youth in clinical and school settings. Second, the consequences of adolescents' smartphone use should be discussed with parents in clinical and school settings. In fact, precocious access to a personal smartphone and the youth's immature control competence increase the risk of dependency more than smartphone-related health risk behaviours concerning sexual activities and cyberbullying.

Moreover, the presence of health risk behaviours, such as binge drinking and drug consumption, should encourage the promotion of specific intervention programs. The presence of inner suffering and the need for psychological support that adolescents reported was not communicated to school authorities or health professionals, and merged into self-harm behaviours that constitute a significant risk factor for subsequent suicide attempts. Thus, improving psychological services inside the school context would constitute a protective factor to prevent suffering. The early detection of self-harm behaviour would allow early intervention.

\section{Acknowledgements \\ The project was born from an idea of Dr. Giovanni Vitali Rosati (President of Italian Society of Pediatrics Tuscany unit) who made a team composed of: Conforti G., De Masi S., Donzelli G., De Luca G., Giannino P., Gonzalez \\ Gonzalez J., La Forgia N., Licustri S., Milone AR., Nobili B., Salvini L., Smorti M., Sperli D. We thank the president of Italian Society of Pediatrics for the support given to the realization of research, the past president of Society (Corsello G.) and the local units presidents of Italian Society of Pediatrics for their useful help: Armiento D.,Baldo E., Biasucci G., Cassata N., Collacciani G.; Conforti G., Felici L., Ferrara P., Gianino P., Marchisio, P., Montanari G., Morlupo M., Mura RM., Nobili B., Rugolotto S., Simonetti MLD., Sperli D. \\ A grateful thanks to Prof. Mimma Bruno who made it possible to spread in Puglia.}

Funding

The authors received no specific funding for this work.

Availability of data and materials

The datasets used and/or analysed during the current study are available from the corresponding author on reasonable request.

\section{Authors' contributions}

GVR contributed substantially to conception and design of the study, and its realization; MS, GVR, JG, AM contributed to the questionnaire; JG provided the online questionnaire; MS contributed to the data analysis and drafted the methods and results section in the manuscript; AM contributed to interpretation of data and drafted the introduction and conclusion section; GVR, JG critically revised the manuscript and final approval of the version to be published. All authors read and approved the final manuscript.

\section{Ethics approval and consent to participate}

The institutional review boards approved the study. The school authorities (headteachers and teachers) were informed about the research project and its goals, and discussed and approved the online questionnaire. The school authorities informed parents of minors about the study and obtained their consent.

Consent for publication

Not applicable.

Competing interests

The authors declare that they have no competing interests. 


\section{Publisher's Note}

Springer Nature remains neutral with regard to jurisdictional claims in published maps and institutional affiliations.

\section{Author details}

${ }^{1}$ Department of Surgical, Medical and Molecular Pathology and Critical Care, University of Pisa, Via Savi 10, 56126 Pisa, Italy. ${ }^{2}$ IRCCS Stella Maris, Scientific Institute of Child Neurology and Psychiatry, Calambrone, Pisa, Italy. ${ }^{3}$ Paediatric Department, USL Toscana Centro, Florence, Italy. ${ }^{4}$ USL Toscana Centro, Florence, Italy.

\section{Received: 12 October 2018 Accepted: 26 April 2019}

Published online: 17 May 2019

\section{References}

1. Bor W, Dean AJ, Najman J, Hayatbakhsh R. Are child and adolescent mental health problems increasing in the 21st century? A systematic review Aust $N$ Z J Psychiatry. 2014;4(7):606-16.

2. Kieling C, Baker-Henningham H. Child and adolescent mental health worldwide: evidence for action. Lancet. 2011:378:1515-25.

3. Kessler RC, Angermeyer M, Anthony JC, et al. Lifetime prevalenceand ageof-onset distributions of mental disorders in the World Health Organization's world mental health survey initiative. World Psychiatry. 2007; 6:168-76.

4. Achenbach TM. The Achenbach system of empirically based Assessemnt (ASEBA): development, findings, theory, and applications. Burlington: University of Vermont Research Center for Children, Youth and Families; 2009.

5. Tick N, van der Ende J, Verhulst F. Ten-year trends in self-reported emotional and behavioral problems of Dutch adolescents. Soc Psychiatry Psychiatr Epidemiol. 2008;43:349-55.

6. Spear LP. Effects of adolescent alcohol consumption on the brain and behaviour. Nat Rev Neurosci. 2018;19(4):197-214

7. McLeod JD, Uemura R, Rohrman S. Adolescent mental health, behavior problems, and academic achievement. J Health Soc Behav. 2012;53(4):482-97.

8. Breslau J, Lane M, Sampson N, Kessler R. Mental disorders and subsequent educational attainment in a US National Sample. J Psych Res. 2008;42:708-16.

9. Mahalik JR, Levine Coley R. Changes in health risk behaviors for males and females from early adolescence through early adulthood. Health Psychol. 2013:32(6):685-94

10. Devenish B, Hooley M, Mellor D. The pathways between socioeconomic status and adolescent outcomes: a systematic review. Am J Community Psychol. 2017:59(1-2):219-38.

11. Smorti M, Guarnieri S. The parental bond and alcohol use among adolescents: the mediating role of drinking motives. Subst use misuse. 2015; 50(12):1560-70.

12. Coghill D. Editorial: do clinical services need to take conduct disorder more seriously. J Child Psychol Psychiatry. 2013;54(9):921-3.

13. Ford T. Practitioner review: how can epidemiology help us plan and deliver effective child and adolescent mental health services? J Child Psychol Psychiatry. 2008 Sep;49(9):900-14.

14. Foy JM, Kelleher KJ, Laraque D. Enhancing pediatric mental health care: strategies for preparing a primary care practice. American Academy of Pediatrics task force on mental health. Pediatrics. 2010;125(Suppl 3):S 87-108

15. Rucci FA, Goodman R, Milone A, et al. Prevalence and correlates of mental disorders among adolescents in Italy: the PRISMA study. Eur Child AdolesC Psychiatry. 2009:18(4):217-26.

16. Campolmi E, Gonzalez J, Bonini G. Le problematiche dell'adolescenza: una ricerca della società italiana di pediatria in collaborazione col MIUR Toscana e il Liceo Michelangiolo di Firenze. Toscana Med. 2018;3:17-9.

17. Pratt BM, Woolfenden SR. Interventions for preventing eating disorders in children and adolescents. Cochrane Database of Systematic Reviews 2002; (2):CD002891. DOl: https://doi.org/10.1002/14651858.CD002891.

18. Golden NH, Schneider M, Wood C, AAP COMMITTEE ON NUTRITION. Preventing Obesity and Eating Disorders in Adolescents. Pediatrics. 2016; 138(3):e2016164

19. Rousseau A, Eggermont S. Media ideals and early adolescents' body image: selective avoidance or selective exposure? Body Image. 2018;26:50-9.

20. Randolph K, Turull P, Margolis A. Cannabis and cognitive Systems in Adolescents. Adolesc Psychiatry. 2013;3(2):135-47.
21. Ganzer F, Bröning S, Kraft S. Weighing the evidence: a systematic review on long-term neurocognitive effects of Cannabis use in abstinent adolescents and adults. Neuropsychol Rev. 2016;26(2):186-222.

22. Hanson $\mathrm{KL}$, Medina $\mathrm{KL}$, Padula CB. Impact of adolescent alcohol and drug use on neuropsychological functioning in young adulthood: 10-year outcomes. J Child Adolesc Subst Abuse. 2011;20(2):135-54.

23. Nguyen-Louie TT, Castro N, Matt GE. Effects of emerging alcohol and marijuana use behaviors on Adolescents' neuropsychological functioning over four years. J Stud Alcohol Drugs. 2015;76(5):738-48.

24. Mayet A, Legleye S, Chau N. Transitions between tobacco and cannabis use among adolescents: a multi-state modeling of progression from onset to daily use. Addict Behav. 2011;36(11):1101-5

25. Holliday ED, Nucero P, Kutlu MG. Long-term effects of chronic nicotine on emotional and cognitive behaviors and hippocampus cell morphology in mice: comparisons of adult and adolescent nicotine exposure. Eur J Neurosci. 2016;44(10):2818-28.

26. Treur JL, Willemsen G, Bartels M. Smoking during adolescence as a risk factor for attention problems. Biol Psychiatry. 2015;78(9):656-63.

27. Torres OV, Tejeda HA, Natividad LA, O'Dell LE. Enhanced vulnerability to the rewarding effects of nicotine during the adolescent period of development. Pharmacol Biochem Behav. 2008;90(4):658-63.

28. Cross SJ, Linker KE, Leslie FM. Sex-dependent effects of nicotine on the developing brain. J Neurosci Res. 2017;95(1-2):422-36.

29. Marcell AV, Burstein GR. Sexual and reproductive health Care Services in the Pediatric Setting. Pediatrics. 2017;140(5):1-15.

30. Van Ouytsel J, Walrave M, Lu Y, Temple JR, Ponnet K The associations between substance use, Sexual behavior, deviant behaviors and Adolescents' engagement in sexting: does relationship context matter? J Youth Adolesc. 2018;2:54-68

31. Olweus D. School bullying: development and some important challenges. Annu Rev Clin Psychol. 2013:9:751-80.

32. Gruber J, Fineran S. Sexual Harassment, Bullying, and School Outcomes for High School Girls and Boys. Violence Against Women. 2016:22(1):112-33.

33. Raskauskas J, Stoltz AD. Involvement in traditional and electronic bullying among adolescents. Dev Psychol. 2007:43(3):564-75.

34. Sourander A, Brunstein Klomek A, Ikonen M. Psychosocial risk factors associated with cyberbullying among adolescents: a population-based study. Arch Gen Psychiatry. 2010;67(7):720-8.

35. Pyzalski J. From cyberbullying to electronic aggression: typology of the phenomenon. EBDs. 2012;17:305-17.

36. Ougrin D. Commentary: self-harm: a global health priority - reflections on Brunner et al. J Child Psychol Psychiatry. 2014;55(4):349-51.

37. Klonsky ED, Muehlenkamp JJ. Self-injury: a research review for the practitioner. J Clin Psychol. 2007:63(11):1045-56.

38. Whitlock J, Knox KL. The relationship between self-injurious behavior and suicide in a young adult population. Arch Pediatr Adolesc Med. 2007:161(7): 634-40

39. Muftić $L R$, Updegrove $A H$. The mediating effect of self-control on parenting and delinquency: a gendered approach with a multinational sample. Int J Offender Ther Comp Criminol. 2018;62(10):3058-76.

40. Hawton K, Bergen H, Waters K. Epidemiology and nature of self-harm in children and adolescents: findings from the multicentre study of self-harm in England. Eur Child Adolesc Psychiatry. 2012;21(7):369-77.

41. Sumner SA, Mercy JA. Violence in the United States: status, challenges, and opportunities. JAMA. 2015:314(5):478-88.

42. Ferrari AJ, Charlson FJ, Norman RE. Burden of depressive disorders by country, sex, age, and year: findings from the global burden of disease study 2010. PLoS Med. 2013;10(11):e1001547.

43. King $S$, Chambers $C T$, et al. The epidemiology of chronic pain in children and adolescents revisited: a systematic review. Pain. 2011;152(12):2729-38.

44. Mcluckie A, Kutcher S. Sustained improvements in students' mental health literacy with use of a mental health curriculum in Canadian schools. BMC Psychiatry. 2014;14:379-85. 